\title{
The Serious Leisure Perspective and the Experience of Leisure
}

\author{
A.J. Veal \\ Published in Leisure Sciences: 11 May 2016 \\ http://dx.doi.org/10.1080/01490400.2016.1189367
}

\begin{abstract}
The serious leisure perspective (SLP), which divides leisure activities into three distinct forms, serious, casual and project-based, has been developed by Robert Stebbins over the last 40 years. This paper evaluates the perspective as theory and as a typology. The theory associated with the SLP, concerning social worlds, identification and optimal leisure lifestyles, is found to be generally untested because it has been largely developed in relation to the serious leisure form only. The validity of the typology is questioned on the grounds that 'seriousness' is a continuum, rather than discrete categories, and that most leisure activities can be engaged in with varying degrees of seriousness. It is proposed that the SLP be replaced by a more flexible, open research approach, the Leisure Experience Perspective, which consolidates features of the SLP and other research traditions and a number of other theoretical perspectives.
\end{abstract}

Keywords: leisure experience; leisure motivation; serious leisure

\section{Introduction}

The serious leisure perspective (SLP) is a typology of leisure activity which has been developed and promulgated by Robert Stebbins as an on-going project since 1974 (Stebbins, 2007, pp.103-5). It has been documented in a series of definitive articles (Stebbins, 1982, 1997, 2005a) and a number of consolidating or stocktaking books which draw together and develop associated research and commentary by Stebbins and others (Stebbins, 1979, 1992, 2001, 2007; Elkington \& Stebbins, 2014). A prodigious volume of empirical research utilizing the perspective has been produced by Stebbins and numerous others over the years, such that it has become an influential presence in the field of leisure studies ${ }^{1}$. The basic feature of the SLP is that leisure activity as a whole is divided into three forms: serious, casual and project-based. As shown in Figure 1, these are further divided into types and subtypes, giving a total of 29 sub-types (or 39 if volunteering is divided into sub-types in all three forms). Each of the leisure forms is characterized by a set of distinguishing qualities, costs and rewards, or benefits in the case of casual leisure. The types, sub-types and activities

\footnotetext{
${ }^{1}$ See www.seriousleisure.net/
} 
within a leisure form therefore share a common set of distinguishing qualities, costs and rewards/benefits.

INSERT: Figure 1. Serious leisure perspective: summary

Source: Based on Elkington \& Stebbins (2014, p.15), with the addition of distinguishing qualities and rewards/costs, listing of project-based-occasional as a 'sub-type' rather than a 'type' and omission of 'devotee work'.

Using mostly qualitative methods, Stebbins and others have empirically confirmed associations between the indicated features and activity types/sub-types for serious leisure activity. The same cannot be said for project-based and casual leisure activities, which have been subject to much less research, despite the latter accounting for an estimated 80 per cent of all leisure activity (Stebbins, 2007, p.134). Nevertheless, the claim is made that: 'so far as known at present, all leisure ... can be classified according to one of the three forms and their several types and sub-types' (Elkington \& Stebbins, 2014, p.14). Furthermore, having been developed from a 'grounded theory' process (Stebbins, 2007, p.122), the SLP is also claimed to be an 'established theory' (Elkington \& Stebbins, 2014, p.197) which 'offers a classification and explanation of all leisure activities and experiences. And it accomplishes this by framing them in the social psychological, social, cultural and historical conditions in which each activity and accompanying experience take place' (Elkington \& Stebbins, 2014, p.14).

These are ambitious claims, but can they be substantiated? The analysis in this paper raises considerable doubts as to whether they can. It is argued that the theoretical constructs claimed to be underpinning the SLP as a whole are conceptually weak, with uneven empirical support. Furthermore, it is argued that the discrete typology which lies at the heart of the SLP is logically unsound. It is concluded that attempts which have been made to present the SLP as an all-embracing framework for the study of leisure experiences are not helpful to the field and a looser, more eclectic approach to the study of leisure experiences would be more appropriate. The claimed theoretical credentials of the SLP are discussed first, followed by an examination of the typology itself and then some suggestions for development of the field.

\section{The SLP as theory}

\section{Theory claims}

It has been claimed that the SLP is a 'truly integrated theoretic perspective' (Stebbins, 2007, p.53), a 'formal grounded theory' (Stebbins, 2007, p.3), an 'established theory' (Elkington \& 
Stebbins, 2014, p.197) and 'a valid and useful explanation of human motivation, group formation, collective action, and the like' (Stebbins, 2007, p.3). Its theoretical scope is said to range from the personal and psychological to the structural and socio-cultural (Stebbins, 2001, pp.22-25). As one reviewer observed, Stebbins appears to be offering 'a complete theory of leisure involvement' (Martin, 2008, p.274).

While generally not as ambitious as Stebbins himself, others have also attributed significant theoretical qualities to the perspective. For example, Blackshaw (2010, p.43) observes that serious leisure has taken leisure studies 'in a new direction from other more conventional approaches which largely tend to focus their critical gaze on the dichotomy between work and leisure'. Gillespie, Lefler and Lerner (2002, p.286) assert that the introduction of the SLP 'heralded a conceptual shift in how leisure was studied'. Worthington (2006, p.21) is of the view that, with the advent of serious leisure, 'the very idea of 'leisure' was turned upside down', while, for Dilley and Scraton (2010, p.125), it constituted a 'significant theoretical development'. Even commentators who suggest substantial change in the perspective endorse its theoretical status. Thus Shen and Yarnal (2010, p.165) refer to 'serious leisure theory' and suggest that Stebbins has provided the 'basis for the primary theoretical development in serious leisure'. Gallant, Arai and Smale (2013, p.92) see serious leisure as a 'theoretical development ...uniquely formed within leisure studies', which 'stands as one of the most significant concepts shaping leisure research over the last 30 years'. Researchers who make use of the SLP in their empirical work often explicitly adopt it as a 'theory' (e.g., Bartram, 2001, p.5; Green \& Jones, 2005, p.166; Kane \& Zink, 2004, p.342; Shinew \& Parry, 2005, p.370; Heley \& Jones, 2013, p.277), a 'theoretical framework' (e.g., Frew, 2006; Gravelle \& Larocque, 2005, p.46) or a 'foundation' (Butler, 2010, p.iii).

A very different view of the SLP is that it is not theoretical at all, but merely typological and descriptive. For example, a reviewer of one of Stebbins' books suggested that readers might find the SLP 'overly taxonomic', in that 'the delineations Stebbins makes between types of leisure careers are often descriptive, lacking in theoretical richness and depth' (Puddephatt, 2007, p.1). Breeze (2013, p.24) describes the SLP as 'overly descriptive'. Jones (2006, p.57) argues that a reorientation of the perspective around the concept of social identity would make it possible 'not only to describe serious leisure activity, but also to explain many aspects of serious leisure behaviour' (emphasis added), implying that the SLP in its current form is only descriptive, not explanatory. Arguably still pertinent after more than twenty years, is Hamilton-Smith's (1993, p.12) observation that, 'perhaps Stebbins and 
others have devoted too much attention to the definition and description of serious leisure rather than its dynamics over time'.

Theory is commonly distinguished from mere description on the basis of the criterion that it explains or offers understanding (Charmaz, 2006, pp.125-128). Three groups of theoretical propositions can be identified in the SLP literature. The first group can be seen as complementary to the perspective and the second as intrinsic, while the third arises from critiques and can be seen as theory deficit. These are discussed in turn below.

\section{Theory content: complementary}

The latest consolidating book includes a chapter on 'The serious leisure perspective in the social sciences', which 'explores the place of the SLP in and its contribution to social science theory' (Elkington \& Stebbins, 2014, p.39). It briefly discusses a number of topics, namely: time; gender; the body; ethnicity; disability; inclusion, exclusion and social class; social capital; consumption; quality of life; well-being; and non-profit studies. Of these topics, only well-being arises in relation to intrinsic theory, and is discussed further below. Further linkages and applications are discussed in seven chapters devoted, respectively, to: tourism and events; consumption; arts, science and heritage administration; library and information science; therapeutic recreation; leisure education, life course and lifelong learning; and deviant leisure. These two sets of discussions explore a wide range of themes, some of which are central to leisure studies generally, but for the most part they remain external to the SLP (Stebbins, 2012b, p. 4), perhaps performing the function of 'framing' the three SLP leisure forms as noted above. There is, therefore, little sign of their impact on the parameters of the SLP, for example in the form-specific lists of distinguishing qualities or costs/rewards.

A number of approaches to the study of the leisure experience, which can be seen as relevant to the SLP and as having theoretical as well as empirical ramifications, have been treated in a less systematic way in the SLP literature, where they tend to be ignored or considered as subsidiary to or components of the SLP or, at best, as complementary to it. They include the following.

- Needs-based research of Tinsley and colleagues (e.g., Tinsley \& Eldredge, 1995) is based on the proposition that leisure experience satisfies needs, but it does not feature in the SLP literature.

- Benefits-based work by Driver and colleagues (e.g., Driver \& Bruns, 1999; Driver, Tinsley \& Manfredo, 1991) merits only a brief mention in Stebbins (2007, p.23). 
- Commitment (Buchanan, 1985; Goff, Fick \& Oppliger, 1997; Mannell, 1993; Shamir, 1988; Tomlinson, 1993), is recognized by Stebbins (2007, p.2) as an 'important attitude' in serious leisure, and as one of its 'most profound consequences' (p.71), but it is ignored in the latest consolidating book (Elkington \& Stebbins, 2014).

- Specialization is founded on the work of Bryan $(1977,1979 / 2008)$ and was developed over approximately the same time period as the SLP (see Cole \& Scott, 1999; Scott \& Shafer, 2001; Scott, 2012; Tsaur \& Liang, 2008), but is viewed by Stebbins (2005b, 2012a; Elkington \& Stebbins, 2014, p.25) as just a version of his conception of a serious leisure career. It arises in the later discussion of the SLP as typology.

- Constraints research provides insights into the process of seeking access to leisure activity and has been shown to complement serious leisure concepts, both generally (Kennelly, Moyle \& Lamont, 2013; Lamont, Kennelly \& Wilson, 2012; Lyu \& Oh, 2015; McQuarrie \& Jackson, 1996) and in relation to women (Dilley \& Scraton, 2010; Jackson \& Henderson, 1995). However, while Stebbins (2007, p. 15; 2016a) admits that the construct is in some way associated with costs in the SLP, it is not mentioned in the latest consolidating book (Elkington \& Stebbins, 2014).

- Enduring involvement has been extensively researched in relation to consumer behavior and applied to leisure experiences (Havitz \& Dimanche, 1990; Jun, Kyle \& Vlachopoulos, 2012; Kyle \& Chick, 2002; Lee \& Scott, 2009; McIntyre,1989) but had merited only a footnote in the SLP literature (Stebbins, 2007, p.23, n.5), until a recent discussion of 'the seriousness dimension of involvement' (Stebbins, 2014, p.32-34).

These approaches are revisited in the concluding section of the paper.

\section{Theory content: intrinsic}

Three theoretical constructs identifiable in the SLP literature can be considered intrinsic to the perspective. Two of them arise from serious leisure distinguishing qualities, namely social worlds and identification with the activity and are discussed below. It is notable that the other four distinguishing qualities of serious leisure and those related to casual and project-based leisure are not presented in the SLP literature as having substantive theoretical dimensions. The third construct examined below, motivation, is related to the rewards system and can be seen as the core theoretical construct of the perspective.

The issue addressed here is the extent to which these theoretical constructs contribute to the SLP project by explaining the distinction between serious, casual and project-based 
leisure forms, and the extent to which they have been tested empirically. Three themes recur in this review: that SLP analysis is often focused more on description and classification than on theory development; that features presented in the SLP context as associated exclusively with the serious leisure form can often also be seen to be, to a greater or lesser extent, features of the casual leisure form; and that empirical testing of theoretical propositions is uneven, due particularly to the lack of comparative research on casual leisure.

\section{Social worlds/tribes}

The concept of social worlds, initially discussed in detail in Stebbins (2001, pp.7-9) and based on the work of Unruh (1980), is incorporated into the SLP as a feature of the serious leisure distinguishing quality of a unique ethos. Serious leisure activities are said to be characterized by the existence of unique social worlds, while both serious and casual leisure are characterized by Maffesoli’s (1996) related concept of modern tribes (Stebbins, 2007, p.64). The similarity of the concept of social world to subculture is recognized by Stebbins (2001, p.8) and he notes that it is therefore possible to 'logically speak about ... social stratification in social worlds'. However, rather than this leading to an opening up of the analysis to explore links with the rich cultural studies tradition in leisure studies and wider social systems of stratification, such as class, he steers his discussion inwards to consideration of the distinction between sub-categories of serious leisure participants, namely participants and devotees. Furthermore, in Stebbins' (2007, p.64) discussion of tribes, he develops his own three-fold typology arranged on a complexity continuum, with social worlds added at the most complex end, in a procrustean exercise to align the concepts of tribes and social worlds with SLP categories. Casual leisure, it seems, is associated only with tribes, serious leisure is associated with both tribes and social worlds (Stebbins, 2007, p. 64). However, there is no evidence in the SLP literature of the distinctions between tribes and social worlds having been explored empirically. The concept of tribe is not mentioned in the latest consolidating book (Elkington \& Stebbins, 2014) so the opportunity to engage with recently researched active dimensions of the behavior of modern tribes (e.g., Cova, Kuznets \& Shankar, 2007) is missed.

\section{Identification}

Serious leisure participants' identification with the activity is currently listed as the sixth distinguishing quality of serious leisure and it 'revolves around the preceding five' (Stebbins, 2007, p.12). If serious leisure participants are found to be particularly motivated by the desire 
to create or confirm an identity, this would lend a potentially dynamic quality to the SLP, in contrast to its relatively static, taxonomic qualities. Stebbins himself has written very little on identification, and in the recent consolidating books it is defined only loosely, being summarized in less than ten lines (Stebbins, 2007, pp.12-13; Elkington \& Stebbins, 2014, p.19). Furthermore, he makes no reference to the extensive theoretical literature on identity generally (e.g., Giddens, 1991) or as related to leisure activity (e.g., Glasser, 1973; Haggard \& Williams, 1992). Nevertheless, qualitative empirical research (e.g., Anderson \& Taylor, 2010; Baldwin \& Norris, 1999; Gibson, Willming \& Holdnak, 2002; Jones, 2000) has confirmed the relationship with serious leisure activity. Jones (2006) has even argued, based on evidence from research on sport fans, that the SLP should be focused primarily on identification, but this suggestion has been ignored by Stebbins, despite apparent support for the idea in his own quantitative structural model of serious leisure (Heo Lee, Kim \& Stebbins, 2012). It is claimed, in contrast, that identification is not associated with the casual leisure form, since it is 'too fleeting, mundane and commonplace to become the basis for a distinctive identity for most people' (Elkington \& Stebbins, 2014, p.19), but no specific empirical evidence is offered to support this assertion. However, the use of the word 'most' introduces a note of ambivalence and empirical studies, such as those of Brown (2007) and Shen and Yarnal (2010), have indeed found that identification with an activity can be as important for casual participants as it is for serious participants. As with social worlds, therefore, identification has not been shown to be exclusively a distinguishing characteristic of the serious form of leisure.

\section{Motivation}

Theory concerning the individual's motivation to participate is arguably the most central to the SLP. It is, however, not linked with any of the distinguishing qualities of the leisure forms but with the rewards system. It has three components: the profit hypothesis; the drive for rewards; and the pursuit of an optimal leisure lifestyle.

The profit hypothesis states that the decision to initiate, and to continue, participation in a serious leisure activity involves a balancing of the rewards experienced and costs incurred, with participation continuing as long as the former outweigh the latter (Elkington \& Stebbins, 2014, p.19). This hypothesis did not arise from the grounded theory work associated with the SLP but from the starting point of Homans' (1974) general theory of social behavior (Stebbins, 1992, p.93). As such, the process is also likely to apply to casual and project-based 
leisure and to work and virtually all human behavior. It is, for example, at the core of economic demand/ consumption theory, with the term 'utility' used in place of 'rewards'.

However, the primary aim of SLP empirical work has not been just to test the proposition that rewards exceed costs for participants, which would be somewhat trivial, but to identify and describe the particular rewards and costs involved for the different leisure forms. While considerable effort has been expended by Stebbins and others in compiling and confirming the relevant lists of rewards and costs, the result remains a basically descriptive exercise, as shown in the 'typological map' in Figure 1. However, the concept of rewards gains theoretical significance in the SLP in light of a second proposition, that the goal of serious leisure participation is 'the drive to experience the rewards of a given leisure activity' (Elkington \& Stebbins, 2014, p.20). Participation in serious leisure is therefore viewed as a form of goal-directed behavior. It might be expected, however, that this would also apply to the other two leisure forms and this is briefly indicated for project-based leisure (Elkington $\&$ Stebbins, 2014, p.31) but only implied for casual leisure (Elkington \& Stebbins, 2014, p.28).

Given that many possible leisure activities are likely to offer the individual an excess of rewards over costs, the question arises as to the process by which individuals choose a set of activities from the array on offer. An explanation of this is offered in the third piece of theory, the search for an optimal leisure lifestyle. This involves the pursuit of one or more serious leisure activities, 'complemented by judicious amounts of casual leisure or projectbased leisure or both' (Stebbins, 1998; Elkington \& Stebbins, 2014, p.30). Serious leisure is seen as an essential ingredient of an optimal leisure lifestyle, while casual and/or projectbased leisure are complementary. If this were found to be the case then serious leisure would clearly be a theoretically and practically significant concept and the major part of the theoretical work of the SLP would lie in the exploration of the optimal leisure lifestyle phenomenon. However, this task has been neglected, both empirically and conceptually, particularly because of the emphasis given to empirical exploration of the 'distinguishing qualities', which play no part in the motivation theory.

The concept of an optimal leisure lifestyle takes us into the age-old philosophical debate on the role and nature of leisure in the 'good life'. This is notably exemplified by the Leisure Aristotleans (Van Moorst, 1982), a source which has been acknowledged by Stebbins (1997, p.117; 2007, p.101). For a sociological approach to studying this issue, however, suitable social variables are required to serve as criteria for optimality. Three are mentioned by Stebbins, namely the realization of 'human potential' and the enhancement of 'quality of life and well-being' (Elkington \& Stebbins, 2014, p.30). Another variable which has been used in 
this context is 'life satisfaction' (Kim, Dattilo \& Heo, 2011; Mannell, 1993). Of these variables, only well-being is pursued in what follows, since it is given most attention in the SLP literature.

The treatment of well-being in the SLP schema is, however, inconsistent. For example, it is identified as one of the specified rewards for casual leisure (Elkington \& Stebbins, 2014, p.30) but not for serious leisure. It is declared to be 'an important by-product of serious leisure' (Elkington \& Stebbins, 2014, pp.47-48) but, because of some of serious leisure's negative aspects, or costs, we should 'avoid postulating an automatic link between serious leisure and well-being'. Empirical testing is sparse. It was referred to in relation to optimal leisure lifestyle in an empirical study of serious sports participants (Stebbins, 2005c) in which it was found that casual leisure 'contributed to overall well-being' as it was used by respondents to 'optimally round out their use of free time' (Elkington \& Stebbins, 2014, p.30). In another study of members of hobbyist and voluntary groups (Stebbins, 2005d) wellbeing was invoked indirectly when respondents were deemed to be living optimal leisure lifestyles because they reported being 'generally satisfied' with their present set of serious and casual leisure activities. However, the samples in these two studies included only people who were engaging in serious leisure activity, so the implied null hypothesis, that an optimal leisure lifestyle is not achievable in the absence of serious leisure, could not be tested. Parker et al. (1993, p.16), however, identified a number of subjects who did not engage in any serious leisure activity and raised, but did not answer, the question as to whether their leisure lives, and by inference their whole lives, should be evaluated as 'deprived or inadequate in some way'. Without reference to specific empirical evidence, Stebbins (2005c, p.119) seems to be in no doubt about this when he declares: 'Many people seem to suffer from a spiritual malaise that their free time, filled exclusively with casual leisure as it is, is only minimally interesting, marginally exciting, if not boring'. However, more than 30 years after the introduction of the leisure lifestyle idea (although not the precise terminology) (Stebbins, 1982, p.253), he has recently admitted, that no one 'has yet carried out a properly controlled study expressly designed to ascertain whether long-term involvement in a form of serious leisure actually leads to significant and enduring increases in feelings of well-being' (Elkington \& Stebbins, 2014, p.48). The question of the optimal leisure lifestyle therefore remains unfinished business for the SLP, despite its key significance for the framework. If the criterion for optimality is to be well-being, then this complex concept requires careful consideration (see, for example, Diener, 2000; Heo, Lee, McCormick \& Pederson, 2010; 
OECD, 2013), but less than a page is devoted to its discussion in the latest consolidating book (Elkington \& Stebbins, 2014, pp.47-48).

The concept of 'leisure lifestyle' merits some attention in its own right. A person's 'leisure lifestyle' can be presumed to exist within a broader 'lifestyle'. Lifestyle has been defined as 'the distinctive pattern of personal and social behaviour characteristic of an individual or a group' (Veal, 1993, p.247), with behavior including: consumption activity; leisure; work (paid or unpaid); civic and religious activity; and activities involved in relationships with partners, family, relatives, friends, neighbors and colleagues. Arguably, most people seek to optimize their lifestyles, with the leisure component being of varying significance. The optimality of the leisure component of lifestyle is likely to be contingent on the nature and relative importance of other domains of life, for example, work and family (Adler, 1970/1996; Anderson, 2011; Lamont, Kennelly \& Wilson, 2012; Super, 1980). Mannell's (1993) exploration of the beneficial role of 'high investment' (equivalent to serious) leisure activities in the lifestyles of retired people offers a baseline study, since his subjects have no paid work commitments and relatively minimal family responsibilities. For other age-groups, however, non-leisure domains of life could be so demanding that an optimal lifestyle might be one which does not include serious leisure. As Hutchinson and Kleiber (2005) establish, when people are feeling vulnerable or stressed, it is often casual rather than serious leisure activity which is vital in enabling them to cope. It is also possible to imagine someone engaged in a range of activities, such as regular exercise activity, attendance at a range of cultural events, reading books, listening to a range of music, and socializing, which could reasonably be deemed to collectively constitute an optimal leisure lifestyle but which would not include any activity meeting the criteria for serious leisure. This could apply to people during certain phases of their lives and to some during the whole of their lives. It follows that a lack of serious leisure in a person's life need not necessarily result in a 'spiritual malaise'.

\section{Intrinsic theory: conclusions}

The consistent feature of these intrinsic theoretical offerings of the SLP is that, having generally been developed almost exclusively in the context of empirical research on single serious leisure activities, their treatment in relation to leisure as a whole, which the SLP is claimed to encompass, is deficient, in both theoretical and empirical terms. The thesis of the SLP involves the proposition that social world/tribal experiences, identification with an activity and contributing essential features of an optimal leisure lifestyle are exclusive 
qualities of a defined list of serious leisure activity sub-types, whereas they are potentially features of all leisure activities to a greater or lesser extent. Such a proposition can be advanced in relation to numerous other theoretical/analytical constructs used in leisure studies, such as those mentioned in the discussion of complementary theory above, namely: needs; benefits; commitment; specialization; constraints; and involvement. Any leisure activity experience can be assessed in terms of the salience of such constructs. This analysis leads to the conclusion that the presence or absence of 'seriousness' is not necessarily the key organizing feature of leisure activity and experience as claimed in the SLP. Leisure is multidimensional and 'seriousness', with its specified list of supporting qualities/costs/rewards, is just one dimension among many. This proposition is further explored in the examination of the SLP as typology below and in the conclusions.

\section{Theory deficit}

Given Stebbins' (2001, pp.22-25) claim that the SLP encompasses structural and sociocultural theory, one of the rare examples of critical commentary on it in the leisure studies literature should be considered. This is the observation by Rojek (2000, p.19), supported by Blackshaw (2010, p.43), that the SLP provides 'no basis for regarding leisure as a lever for social change'. Here social change refers primarily to relationships at the macro-societal level. This claim could have been partially countered in the early days of the serious leisure project when its central raison d'être was that serious leisure could play a role in response to, if not as a lever for, social change in the form of the widely anticipated work-time-reduced future (Stebbins, 1982, pp.251-4; 1992, pp.1-3). The pursuit of serious leisure was proposed as 'the remedy to help solve the social problem of meaningless empty leisure' (Stebbins, 1992, p.126): it was seen as being poised to solve a looming societal problem. The theme persisted into the 1990s and beyond, in the context of an anticipated 'leisure age' (Stebbins, 1998, p.129) or 'job-reduced future' (Stebbins, 2001, p.147), based on the more dystopian post-work ideas of Rifkin (1995) and Aronowitz and DiFazio (1994). However, in recent SLP writings, in an era of longer working hours, 'time-squeeze' and work-life balance problems for some, and growing job-insecurity for others, the role of serious leisure, if any, in this changing social context is not addressed.

Social change is also a concern of Kuentzel (2012) in his comparison of serious leisure and recreation specialization. One of his arguments is that serious leisure is incapable of dealing with social change because of its structural-functional nature, in contrast to recreation specialization which can 'accommodate critical theories of leisure behavior' (p.376). In fact, 
both recreation specialization and the SLP are potentially multi-paradigmatic. However, while Stebbins (1992, p.133) distances the SLP from the 'macro-sociological claims of the Marxists', downplays the significance of class issues (Elkington \& Stebbins, 2014, pp. 4445), and believes that 'serious leisure can contribute significantly to communal and even societal integration' (Stebbins, 2001, p.152), the perspective is not necessarily intrinsically conservative. For example, Blackshaw and Crabbe (2004, p.51) see serious leisure as being a particularly suitable categorization for some forms of 'leisure and styles of engagement that have otherwise been seen as 'unproductive' or 'deviant', such as certain youth subcultures. Furthermore, inasmuch as the SLP is typically focussed on group activity, Rojek (1999, p.87), while not using the terminology of serious leisure, has noted that, historically, in Britain, 'art clubs, choir groups, drama groups, Bible and poetry classes and rambling associations all functioned as conduits for the exchange and development of disaffected and oppositional values'.

Kuentzel's brief comments have another dimension which should be highlighted. Basically, he views the SLP as a closed and static system, in contrast to the open and dynamic nature of recreation specialization. As suggested by the comment from HamiltonSmith (1993, p.12), quoted above, and Breeze's (2013) frustrations with the SLP in regard to the changing environment of roller-derby, it is possibly the over-concern with typologyrelated description and the definitional tasks of the SLP which has resulted in a neglect of the issue of societal change and changes in the nature and social status of activities. More broadly, while Stebbins (2001, p.24) has in the past claimed that history is part of the SLP, and has recognized that application of the SLP to the contrasting and changing conditions and cultures of developing countries is a challenge (Elkington \& Stebbins, 2014, pp.203-205), historical and broader cultural traditions, do not feature in its key parameters.

\section{The SLP as typology}

Our main concern here is with the nature and validity of the discrete three-form leisure activity typology at the heart of the SLP. Seeds of doubt about this format were sown by Stebbins himself in his first definitive paper on serious leisure published more than 30 years ago, when he stated:

seriousness and casualness ... are merely poles of a complicated dimension along which individuals may be ranked by their degrees of involvement in a particular activity. Hence, a more sophisticated, research-informed construct will likely abandon eventually this primitive categorical terminology for terminology conveying continuousness. 
(Stebbins, 1982, p.255)

This observation was repeated in 1992 (Stebbins, 1992, p.6) but, while the idea of a continuum of leisure experiences associated with the same activity was being pursued within other research frameworks, such as specialization (e.g., Kuentzel \& Haberlein, 1997) and involvement (Havitz \& Dimanche, 1997), it was not followed up in serious leisure for some decades. Shen and Yarnal (2010) identified a number of serious leisure studies which had failed to confirm the dichotomous (serious/casual) nature of the phenomenon, or the exclusive identification of individual activities with specific SLP forms. It was found that single leisure activities could engender a mixture of casual and serious experiences of varying intensity. Thus, in a study of participation in a single genre of dance, Brown (2007) found that some participants fitted into the casual category and some into the serious category, while some fell between the two, while distinctive sub-groups were found among both casual and serious participants. Studying a range of activities, Parker, Hamilton-Smith and Davidson (1971) introduced a partly serious category, while Sieghaler and O’Dell (2003) divided serious golf participants into four groups, including a social group whose participation patterns seemed decidedly casual in nature.

Shen and Yarnal's (2010) own quantitative empirical study of members of a social club reported a range of 'serious' and 'casual' experiences. They therefore concluded that, rather than classifying an activity into a serious/casual dichotomy, their own and others' serious leisure studies were actually locating experiences on a serious/casual continuum. Other serious leisure studies have supported these findings, with participants in the same activity being found to be enjoying a mix of serious and casual experiences. These have included: sport fans (Jones, 2000; Gibson et al., 2002); participants in athletic events (Derom \& Taks, 2011); gun-collectors and sky-divers (Anderson \& Taylor, 2010); and bridge-players (Scott \& Godbey, 1992). Such studies can be said to have contributed to the grounded theory-based evolution of the SPL, but they are ignored in the latest consolidating book (Elkington \& Stebbins, 2014): of the studies mentioned in this and the previous paragraph, only that of Sieghaler and O'Dell (2003) is referenced and then only in relation to subdivision of the serious leisure form into career-related categories.

On reflection, however, it has hardly needed the prism of the SLP and its prescribed program of detailed empirical study to establish that one leisure activity can be experienced in different ways by different participants at the same time and by the same person at different times. The proposition was exemplified in Stebbins' own comment: 'the dabbling of 
a child on the piano (casual leisure) may lead to a serious leisure goal of becoming an amateur musician (serious leisure) on the instrument' (Elkington \& Stebbins, 2014, p.4). He might also have added that, if the child were to embark on a program of tuition to achieve a certain level of competency at piano playing, this would be a project-based leisure exercise which could enable the child to continue to play the piano as a casual or serious leisure activity in the future. Stebbins (2012a, p. 373; 2014, p.33) also gives examples of activities (tennis, bird-watching, swimming and piano-playing) in which some people may 'forever dabble' (the casual leisure form) even though they are 'capable of being pursued seriously' This idea is reinforced by common usage of the term 'serious' (Stebbins, 2007, p.121): to 'take an activity seriously' implies that the same activity can also be participated in notseriously, that is, casually. As Shen and Yarnal (2010, p.165) put it: 'Serious and casual leisure pursuits can be found in practically any activity'. Yet formal presentations of the SLP continue to be present seriousness as a form-specific typology rather than a continuum (e.g., Stebbins, 2015a, p.16; 2015b, p.13; 2016b).

Two technical features of the SLP indicate the multi-form nature of activities and so undermine its internal consistency. First, even in formal presentations of the perspective, as in Figure 1, there are activity sub-types which appear in more than one leisure form: volunteering and entertainment both appear in all three forms, while liberal arts and making /tinkering appear in two forms. On the other hand, the obviously multi-form nature of the key leisure activity of sport is hidden by idiosyncrasies of sub-type definitions and terminology. Conversely, there are 'rewards' which are common to both serious and casual leisure, namely 'regeneration/ re-creation'/'re-creation' and 'personal relationships'/ 'social attraction'.

Second, while the procedures for allocating an activity-experience to an SLP form are not spelled out in detail in the SLP literature, if some reasonable assumptions are made, they point to uncertainties. Thus, considering the six distinguishing qualities of serious leisure, it seems unlikely that empirical work to assess their salience in a given leisure participation situation would always produce clear 'yes/no' responses. As some of the SLP empirical research demonstrates, the strength of association between a distinguishing quality and an activity-experience varies from activity to activity, from situation to situation and from individual to individual. Some, situations or individual experiences of the same activity are likely to emerge as more serious than others, supporting the idea of a continuum.

Two other contributions to the serious leisure literature support the idea that leisure experiences lie on a continuum. First, Scott (2012) proposed a 'marriage' between the SLP and recreation specialization, a field of study which, as noted above, has also developed over 
the last four decades and, since its inception, has been based on the idea of a continuum of experience (Lee \& Scott, 2013; Scott \& Shafer, 2001). In making this proposal, Scott (2012, p.368) observed: 'there is a diversity of commitment and seriousness within virtually all leisure activities' and he also coined the term 'SL-CL continuum'. In a response to these comments Stebbins (2012a, p.372), while not accepting the marriage proposal, endorsed the idea of closer cross-fertilization with recreation specialization ideas, and seemed to accept the continuum concept, although its validity had 'some limitations' (p.373). He declared that: 'the casual leisure-serious leisure (CL-SL) (sic) continuum as it is called these days has a reasonably long history'. However, the history he refers to is not of a continuum covering all leisure forms, but his own and other researchers' sub-division of serious leisure participants into career-related sub-categories: neophyte, participant, moderate devotee and core devotee. The main 'limitation' described is that 'movement along the CL-SL continuum is by no means inevitable' (p.373). He refers to the example of those people who 'forever dabble' (i.e., participate in casual mode) in activities which can also be engaged in in serious mode, as noted above. A second example is the converse, that in the case of activities requiring considerable up-front skills, participants may miss the dabbling-neophyte stages altogether. There are two problems with this argument. First, proponents of the use of continua in analyzing leisure experience do not suggest that all participants must inevitably move along it in some standard way. Indeed, Scott and Shafer (2001, p. 319), in discussing the recreation specialization continuum, observe that progression along the continuum 'is not a typical career path pursued by recreation participants'. Thus, while it is possible to classify participants according to varying levels or types of skill, experience and commitment, and place them at a point on a continuum, how they get to that point, and where they proceed from there, if anywhere, is likely to vary across individuals, activities and contexts. Second, Stebbins seems to ignore the point, made above, that if some people can be 'forever dabblers' in activities that can also be engaged in seriously, then this places such participation on a common continuum: the activity, e.g. playing football, is not either a casual activity or a serious activity, it can be participated in in either mode. Arguably, this is the case for most leisure activities. Stebbins (2014, p.34) comes very close to acknowledging this in a recent graphic, in which casual leisure/dabbling and project-based leisure form an antecedent stage of the 'SLP involvement scale'.

The second additional contribution to the move to introduce a continuum to the SLP is the introduction of quantification. This involved the development of the Serious Leisure Inventory and Measure (SLIM) scale by a group of researchers of which Stebbins was a 
member (Gould, Moore, Mcguire \& Stebbins, 2008). A comparable scale, combined with items relating to specialization, was developed independently by Tsaur \& Liang (2008). These scales were based on a number of items (attitude statements) corresponding to the serious leisure distinguishing qualities, which were scored by participants using a Likert-type scale. The SLIM scale was utilized in a further development in quantification, the structural model of serious leisure which, introduced by another team of which Stebbins was a member (Heo et al., 2012), modelled the correlational links among serious leisure distinguishing qualities as variables. As Shen \& Yarnal (2010, p.166) point out, the use of a scale 'inadvertently defies the dichotomous SL-CL conception by constructing a tool that allows for explicitly assessing the degrees to which the six purported SL dimensions may be experienced'. While the SLIM scale and the structural model are confined to the serious leisure form only, the study conducted to verify the scale (Gould et al., 2008) raised the question: is a low score on one or more serious leisure qualities an indication of casualness? A further question that might be asked is: why could not a version of these tools also be developed for casual leisure? Then, in line with the idea of a continuum spanning both serious and casual leisure, the possibility arises that a combined scale and a single model covering all three forms might be developed. Such possibilities are, however, not mentioned in the most recent discussion of future developments of the SLP (Elkington \& Stebbins, 2014, pp.197-207).

It is notable that the above discussions of the SLP tend not to include consideration of project-based leisure. However, since it is described as 'capable of generating many of the rewards experienced in serious leisure' but 'does not demand long-term commitment' (Elkington \& Stebbins, 2014, p.31), it can be seen as 'serious leisure lite', implicitly lending support to the continuum idea. It is therefore not given separate attention as a distinct form in the following discussion.

Given these significant developments, dating back to at least 2008, and seemingly endorsed by Stebbins, it is puzzling to find that, in a recent statement on developments in the SLP since 2007, there is no mention of the existence of the SL-CL continuum, the SLIM scale or the structural model (Stebbins, 2015c). This omission occurs in the preface to the paperback edition of the 2007 consolidating book in which the development of the SLIM scale had been keenly anticipated (Stebbins, 2007, p.36; 2015, p.36). The developments are also ignored in the latest consolidating book (Elkington \& Stebbins, 2014). In the latter case it is possible that such matters were considered too advanced for what is designed as a student textbook, but they are not referred to even in 'further reading' lists or in the final chapter on 
the future of the perspective. Stebbins (2014, pp.31-33) acknowledges the CL-SL continuum in a recent book on careers in leisure, but this acknowledgement does not appear in the opening chapter devoted to the standard typological presentation of the SLP (pp.3-27), so the incompatibility between the two approaches is not addressed. Meanwhile, empirical studies continue to be published using the dichotomy form of the SLP, without any reference to these continuum-related developments.

The contributors discussed above have tended not to follow their arguments to their logical conclusions, which would threaten the distinctiveness of the SLP. Shen and Yarnal (2010, p.177), while using challenging terminology in the title of their paper ('Blowing open the serious leisure-casual leisure dichotomy') and being quite critical of the SLP in general, are essentially reformist, describing their contribution as 'an effort to advocate an alternative conception that bridges the SL-CL dichotomy'. Scott (2012), while equally critical of the dichotomous nature of the SLP, nevertheless proposes a 'marriage' between the SLP and his preferred framework, recreation specialization. The SLIM proposals themselves contain the seeds of a root-and-branch reform of the SLP through consideration of the implications of low scores, but these appear not to have been followed up in the eight years since publication. These analyses are presented as contributions to the further development of the SLP, but they are potentially more fundamental than that.

The discussions establish that, with the casual-serious couplet viewed as a continuum rather than two separate concepts, and with participation in virtually any leisure activity being seen as possible in varying degrees of seriousness or casualness, the notion of distinct lists of leisure activity sub-types labelled 'serious', 'casual' and 'project-based'- as summarized in Figure 1 - is not appropriate. It further follows that the three lists of distinguishing qualities could also each be seen as a continuum and be combined into a single consolidated list of qualities applicable, to a greater or lesser extent, to any leisure activity.

It would then follow that the same process of consolidation could be applied to costs/ rewards. In fact, the difference between 'distinguishing qualities' and 'costs/rewards' is hard to sustain. The obvious illustration of this is that the second distinguishing quality of serious leisure consists of nine 'durable benefits' which are almost identical to its 'rewards'. It is explained in Elkington \& Stebbins (2014, p.20) that rewards are 'antecedent conditions' for individuals deciding whether or not to participate, while durable benefits are 'outcomes' for actual participants, but a cursory examination of the two lists reveals that they could all, to a greater or lesser extent, be both antecedents and outcomes. This parallels the SERVQUAL consumer research approach to comparing consumers' anticipation of satisfaction prior to 
purchase of a good or service with actual satisfaction during or following consumption (Williams, 1998).

The above analysis has implications for the core structure of the SLP. The discrete typology of activity sub-types disappears. A consolidated list of the 39 distinguishing qualities, costs and rewards nevertheless remains as a useful list of potential features of leisure activity-experiences. They are, however, no longer form-specific but are applicable, with varying degrees of saliency and intensity, to any leisure activity-experience. This could be studied either qualitatively or quantitatively or both. In quantitative terminology, any one person's activity-experience would be assessed, or scored, and would therefore occupy a unique position in a multi-dimensional conceptual space. Some clustering of individuals with similar profiles might be found, possibly along a seriousness, or some other, continuum. Based on such a scenario, research on the seriousness dimension of leisure would no longer be classificatory but would be qualitative, descriptive and comparative, as much of it is, in practice, already.

\section{Conclusions}

The conclusions of the above theoretical and typological reviews of the SLP are therefore similar: the discrete activity typology and associated form-specific distinguishing qualities and costs/rewards are not a valid representation of the leisure experience domain.

Lest this be viewed as an entirely negative exercise, however, it is appropriate to consider a potential way forward in regard to the study of leisure experiences. It is not possible in this paper to develop detailed proposals, but a potential direction can be indicated. Some 30 years ago, Rojek $(1985$, p.4) referred to the phenomenon of 'multi-paradigmatic rivalry' in leisure theory; what is being proposed here is multi-paradigmatic cooperation. As the discussion of complementary theory above indicates, there are numerous existing paradigms, frameworks and approaches which a researcher might consider working with when examining leisure experiences. Six such frameworks addressing leisure experiences are listed above, all seeking to understand the leisure experience phenomenon. Three of the six commitment, specialization and involvement - are based on the idea of a continuum format, which, it is argued in this paper, is the logical format for the seriousness dimension. While these frameworks often overlap, each highlights particular variables and constructs and ways of assessing them. 
It is proposed that variables or constructs from these frameworks and approaches, including the SLP and key variables from the broad field of leisure studies, be considered as the starting point for research on leisure experience. A tentative draft of such a list is presented in Table 1, divided into three groups: characteristics of experiences; characteristics of individuals; and context.

INSERT: Table 1. Draft checklist of leisure activity-experience variables/constructs

The idea of drawing on features of different frameworks is not entirely original. For example, there have been proposals for linking involvement with constraints (Lee \& Scott, 2009) and with commitment (Iwasaki \& Havitz, 2004; Kim, Scott \& Crompton, 1997) and for linking the SLP with specialization (Scott, 2012; Cole \& Scott, 1999; Lee \& Scott, 2013; Lyu \& Oh, 2015; Tsaur \& Liang, 2008), with constraints (Kennelly et al., 2013; Lamont, Kennelly \& Moyle (2015); McQuarrie \& Jackson, 1996; Stalp, 2006); and with commitment (Tomlinson, 1993). This proposal takes these ideas a step further to consider a wider range of frameworks/constructs.

While some rationalization and refinement of the draft list of variables is likely to be possible, as is extension, it is a somewhat daunting list. However, the research literature collectively indicates that all the variables listed are candidates for consideration when seeking to describe and understand the diversity and complexity of leisure experiences. While individual existing frameworks could continue to function, awareness of variables and constructs from other frameworks might stimulate development and linkages in both conceptual and theoretical terms and in regard to qualitative and/or quantitative data collection and analysis. This remains for future consideration.

In outlining the history of the SLP, Stebbins (2007, p.2) indicated that he had considered calling his framework the 'leisure experience perspective', referring to Mannell's (1999) precedent. Shen and Yarnal (2010), in their study challenging the SL-CL dichotomy, developed a 'Leisure Experience Characteristic' instrument, while Gallant et al. (2013), in their proposals for reform of the SLP, advocated a change of emphasis from the classification of activities to the study of experiences. It seems, therefore, that there may be an emerging consensus that what is now required to progress the exploration of leisure experiences in all their diversity is a Leisure Experience Perspective, which seems a suitable label for the proposed approach. 


\section{Note}

I am grateful to the anonymous referees of this and an earlier version of the paper for their helpful, constructive comments.

\section{References}

Adler, M.J. (1970/1996). The time of our lives: the ethics of common sense. New York: Fordham University Press.

Anderson, L. (2011). Time is of the essence: An analytic autoethnography of family, work, and serious leisure. Symbolic Interaction, 34, 133-157.

Anderson, L, \& Taylor, J. D. (2010). Standing out while fitting in: serious leisure identities and aligning actions among skydivers and gun collectors. Journal of Contemporary Ethnography, 39, 34-59.

Aronowitz, S., \& DiFazio, W. (1994). The jobless future. Minneapolis, MN: University of Minnesota Press.

Baldwin, C.K., \& Norris, P.A. (1999). Exploring the dimensions of serious leisure: love me love my dog. Journal of Leisure Research, 31, 1-17.

Bartram, S. A. (2001). Serious leisure careers among whitewater kayakers: A feminist perspective. World Leisure Journal, 43, 4-11.

Blackshaw, T. (2010). Leisure. London: Routledge.

Blackshaw, T., \& Crabbe, T. (2004). New perspectives on sport and 'deviance'. London: Routledge.

Breeze, M. (2013). Analysing 'seriousness' in roller derby: Speaking critically with the serious leisure perspective. Sociological Research Online, 18, 23 <www.socresonline.org.uk/18/4/ 23.html> 10.5153/sro.3236.

Brown, C.A. (2007). The Carolina shaggers: dance as serious leisure. Journal of Leisure Research, 39, 623-647.

Bryan, H. (1977). Leisure value systems and recreational specialization. Journal of Leisure Research, 9, 174-187.

Bryan, H. (1979/2008). Conflict in the great outdoors. Tuscaloosa, AL: University of Alabama Press.

Buchanan. T. (1985). Commitment and leisure behavior: a theoretical perspective. Leisure Sciences, 7, 401-420.

Butler, E. (2010). Equestrianism: serious leisure and inter-subjectivity. Master of Arts thesis, Colorado State University.

Cole, J. S., \& Scott, D. (1999). Segmenting participation in wildlife watching: a comparison of casual wildlife watchers and serious birders. Human Dimensions of Wildlife, 4, 44-61.

Charmaz, K. (2006). Constructing grounded theory. London: Sage.

Cova, B., Kozinets, R.V., \& Shankar, A. (Eds) (2007). Consumer tribes. Oxford: Butterworth-Heinemann.

Derom, I., \& Taks, M. (2011). Participants' experiences in two types of sporting events: a quest for evidence of the SL-CL continuum. Journal of Leisure Research, 43, 383-402.

Diener, E. (2000). Subjective well-being: the science of happiness and a proposal for a national index. American Psychologist, 55, 34-43.

Dilley, R.E., \& Scraton, S.J. (2010). Women, climbing and serious leisure. Leisure Studies, $29,125-142$.

Driver, B.L., \& Bruns, D.H. (1999). Concepts and uses of the Benefits Approach to Leisure. In E.L. Jackson \& T.L. Burton (Eds), Leisure studies: prospects for the twenty-first century (pp.349-370). State College, PA: Venture. 
Driver, B.L., Tinsley, H.E.A., \& Manfredo, M.J. (1991). The Paragraphs about Leisure and Recreation Experience Preference scales: results from two inventories designed to assess the breadth of the perceived psychological benefits of leisure. In B.L. Driver, P.J. Brown \& G.L. Paterson (Eds), Benefits of leisure (pp.263-286). State College, PA: Venture.

Elkington, S., \& Stebbins, R.A. (2014). The serious leisure perspective: an introduction. London: Routledge.

Frew, E.A. (2006). Comedy festival attendance: serious, project-based or casual leisure? In S. Elkington, I. Jones \& L. Lawrence (Eds), Serious leisure: extensions and applications (pp.105-122). Eastbourne, UK: Leisure Studies Association.

Gallant, K., Arai, S., \& Smale, B. (2013). Celebrating, challenging and re-envisioning serious leisure. Leisure/Loisir, 37, 91-109.

Gibson, H., Willming, C. \& Holdnak, A. (2002). 'We're Gators, not just Gator fans': serious leisure and University of Florida football. Journal of Leisure Research, 34, 397-425.

Giddens, A. (1991). Modernity and self-identity: self and society in the late modern age. Cambridge: Polity.

Gillespie, D.L., Lefler, A., \& Lerner, E. (2002). If it weren't for my hobby, I'd have a life: dog sports, serious leisure, and boundary negotiations. Leisure Studies, 21, 285-304.

Glasser, R. (1973). Leisure and the search for a satisfying identity. In M.A. Smith, S. Parker \& C.S. Smith (Eds), Leisure and society in Britain (pp.56-68). London: Allen Lane.

Goff, S.J., Fick, D.S., \& Oppliger, R.A. (1997). The moderating effect of spouse support in the relation between serious leisure and spouse's perceive leisure-family conflict. Journal of Leisure Research, 29, 47-60.

Gould, J., Moore, D., McGuire, F., \& Stebbins, R.A. (2008). Development of the serious leisure inventory measure. Journal of Leisure Research, 40, 47-68.

Gravelle, F., \& Larocque, L. (2005). Volunteerism and serious leisure: the case of the Francophone Games. World Leisure Journal, 47, 45-51.

Green, B.C., \& Jones, I. (2005). Serious leisure, social identity and sport tourism. Sport in Society, $8,164-81$.

Haggard, L.M., \& Williams, D.R. (1992). Identity affirmation through leisure activities: leisure symbols of the self. Journal of Leisure Research, 24, 1-18.

Hamilton-Smith , E. (1993). In the Australian bush: some reflections on serious leisure. World Leisure and Recreation, 35, 10-13.

Havitz, M.E., \& Dimanche, F. (1990). Propositions for testing the involvement construct in recreational and tourism contexts. Leisure Sciences, 12, 179-195.

Havitz, M.E., \& Dimanche, F. (1997). Leisure involvement revisited: conceptual conundrums and measurement advances. Journal of Leisure Research, 29, 245-278.

Heley, J., \& Jones, L. (2013). Growing older and social sustainability: considering the "serious leisure" practices of the over 60s in rural communities. Social \& Cultural Geography, 14, 276-299.

Heo, J., Lee, I. H., Kim, J., \& Stebbins, R.A. (2012). Understanding the relationships among central characteristics of serious leisure: An empirical study of older adults in competitive sports. Journal of Leisure Research, 44, 450-62.

Heo, J., Lee, Y., McCormick, B.P., \& Pedersen, P.M. (2010). Daily experiences of serious leisure, flow and subjective well-being of older adults. Leisure Studies, 29, 207-225.

Homans, G.C. (1974). Human behavior: its elementary forms. New York: Harcourt, Brace, Jovanovich.

Hutchinson, S.L., \& Kleiber, D.A. (2005). Gifts of the ordinary: casual leisure's contributions to health and well-being. World Leisure Journal, 47, 2-16. 
Iwasaki, Y., \& Havitz, M.E. (2004). Examining relationships between leisure involvement, psychological commitment and loyalty to a recreation agency. Journal of Leisure Research, 36, 45-72

Jackson, E.L., \& Henderson, K.A. (1995). Gender-based analysis of leisure constraints. Leisure Sciences, 17, 31-51.

Jones, I. (2000). A model of serious leisure identification: the case of football fandom. Leisure Studies, 19, 283-298.

Jones, I. (2006). Examining the characteristics of serious leisure from a social identity perspective. In S. Elkington, I. Jones \& L. Lawrence (Eds), Serious leisure: extensions and applications (pp.47-60). Eastbourne, UK: Leisure Studies Association.

Jun, J., Kyle, G.T., \& Vlachopoulos, S.P. (2012). Reassessing the structure of enduring leisure involvement. Leisure Sciences, 34, 1-18.

Kane, M.J., \& Zink, R. (2004). Package adventure tours: markers in serious leisure careers? Leisure Studies, 23, 329-346.

Kennelly, M., Moyle, B., \& Lamont, M. (2013). Constraint negotiation in serious leisure: A study of amateur triathletes. Journal of Leisure Research, 45, 466-484.

Kim, J., Dattilo, J., \& Heo, J. (2011). Taekwando participation as serious leisure for life satisfaction and health. Journal of Leisure Research, 43, 545-559.

Kim, S.S., Scott, D., \& Crompton, J.L. (1997). An exploration of the relationships among social psychological involvement, commitment, and future intentions in the context of birdwatching. Journal of Leisure Research, 29, 320-341

Kuentzel, W.F. (2012). Comment on Scott: is integration better? Leisure Sciences, 34, 37576.

Kuentzel, W.F., \& Heberlein, T.A. (1997). Social status, self-development and the process of sailing specialization. Journal of Leisure Research, 29, 300-319.

Kyle, G., \& Chick, G. (2002). The social nature of leisure involvement. Journal of Leisure Research, 34, 426-48.

Lamont, M., Kennelly, M., \& Wilson, E. (2012). Competing priorities as constraints in event travel careers. Tourism Management, 33, 1068-1079.

Lamont, M., Kennelly, M., \& Moyle, B.D. (2015). Toward conceptual advancement of costs and perseverance within the serious leisure perspective. Journal of Leisure Research, 47, 647-654.

Lee, J-H., \& Scott, D. (2009). The process of celebrity fans' constraint negotiation. Journal of Leisure Research, 41, 137-155.

Lee, J-H., \& Scott, D. (2013). Empirical linkages between serious leisure and recreational specialization. Human Dimensions of Wildlife, 18, 450-462.

Lyu, S.O., \& Oh, C. (2015). Bridging the conceptual frameworks of constraints negotiation and serious leisure to understand leisure benefit realization. Leisure Sciences, 37, 176193.

Maffesoli, M. (1996). The time of the tribes, decline of individualism in mass society. London: Sage.

Mannell, R.C. (1993). High-investment activity and life satisfaction among older adults: committed, serious leisure and flow activities. In J.R. Kelly (Ed.) Activity and aging: staying involved in later life (pp.125-145). Newbury Park, CA: Sage.

Mannell, R.C. (1999). Leisure experience and satisfaction. In E.L. Jackson \& T.L. Burton (Eds), Leisure studies: prospects for the twenty-first century (pp.235-252). State College, PA: Venture.

Martin, D.C. (2008). Review of 'Serious leisure: a perspective for our time' by Robert Stebbins. Contemporary Sociology, 37, 274-275. 
McIntyre, N. (1989). The personal meaning of participation: enduring involvement. Journal of Leisure Research, 21, 167-179.

McQuarrie, F., \& Jackson, E.L. (1996). Connections between negotiation of leisure constraints and serious leisure: An exploratory study of adult amateur ice skaters. Society and Leisure, 19, 459-483.

Organization for Economic Cooperation and Development (OECD) (2013). OECD guidelines on measuring subjective well-being. Paris: OECD Publishing.

Parker, S., Hamilton-Smith, E., \& Davidson, P. (1993). Serious and other leisure: thirty Australians. World Leisure and Recreation, 35, 14-18.

Puddephatt, A.J. (2007). Review of 'Serious leisure: a perspective for our time', by Robert Stebbins. Canadian Journal of Sociology Online, available at: www.cjsonline/reviews/ seriousleisure.html, accessed Dec. 2013.

Rifkin, J. (1995). The end of work. New York; G.P. Putnam's Sons.

Rojek, C. (1985). Capitalism and leisure theory. London: Tavistock.

Rojek, C. (1999). Deviant leisure: the dark side of free-time activity. In E.L. Jackson \& T.L. Burton (Eds), Leisure studies: prospects for the $21^{\text {st }}$ century (pp.81-96). State College, PA: Venture.

Rojek, C. (2000). Leisure and culture. Basingstoke, UK: Macmillan.

Scott, D. (2012). Serious leisure and recreation specialization: an uneasy marriage. Leisure Sciences, 34, 366-371.

Scott, D., \& Godbey, G.C. (1992). An analysis of adult play groups: social versus serious participation in contract bridge. Leisure Sciences, 14, 47-67.

Scott, D., \& Shafer, C.S. (2001). Recreational specialization: a critical look at the construct. Journal of Leisure Research, 33, 319-343.

Shamir, B. (1988). Commitment and leisure. Sociological Perspectives, 31, 238-258.

Shen, X.S., \& Yarnal, C. (2010). Blowing open the serious leisure-casual leisure dichotomy: what's in there? Leisure Sciences, 32, 162-179.

Shinew, K.J., \& Parry, D.C. (2005). Examining college students' participation in the leisure pursuits of drinking and illegal drug use. Journal of Leisure Research, 37, 364-386.

Siegenthaler, K.L., \& O'Dell, I. (2003). Older golfers: serious leisure and successful aging. World Leisure Journal, 45, 45-52.

Stalp, M. (2006). Negotiating time and space for serious leisure: Quilting in the modern US home. Journal of Leisure Research, 38, 104-132.

Stebbins, R.A. (1979). Amateurs: on the margins between work and leisure. Beverly Hills, CA: Sage.

Stebbins, R.A. (1982). Serious leisure: a conceptual statement. Pacific Sociological Review (now Sociological Perspectives), 5, 251-272.

Stebbins, R.A. (1992). Amateurs, professionals and serious leisure. Montreal: McGillQueen's University Press.

Stebbins, R.A. (1997). Casual leisure: a conceptual statement. Leisure Studies, 16, 17-26.

Stebbins, R.A. (1998). After work: the search for an optimal leisure lifestyle. Calgary, Alberta: Detselig.

Stebbins, R.A. (2001). New directions in the theory and research of serious leisure. Lewiston, NY: Edwin Mellen Press.

Stebbins, R.A. (2005a). Project-based leisure: theoretical neglect of a common use of free time. Leisure Studies, 24, 1-12.

Stebbins, R.A. (2005b). Recreational specialization: serious leisure and complex leisure activity. Leisure Studies Association Newsletter, 70, 11-13.

Stebbins, R.A. (2005c). Challenging mountain nature: risk, motive and lifestyle in three hobbyist sports. Calgary, Alberta: Detselig. 
Stebbins, R.A. (2005d). Inclination to participate in organized serious leisure: an exploration of the role of costs, rewards and lifestyles. Leisure/Loisir, 29, 183-201.

Stebbins, R.A. (2007). Serious leisure: a perspective for our time. New Brunswick, NJ: Transaction.

Stebbins, R.A. (2012a). Comment on Scott: recreation specialization and the CL-SL continuum. Leisure Sciences, 34, 372-374.

Stebbins, R.A. (2012b). The idea of leisure. New Brunswick, NJ: Transaction.

Stebbins, R.A. (2014). Careers in serious leisure. Basingstoke, UK: Palgrave Macmillan.

Stebbins, R.A. (2015a). The interrelationship of leisure and play. Basingstoke, UK: Palgrave Macmillan.

Stebbins, R.A. (2015b). Leisure and positive psychology. Basingstoke, UK: Palgrave Macmillan.

Stebbins, R.A. (2015c). Preface to the paperback edition. In Serious leisure: a perspective for our time (pp.xiii-xviii). New Brunswick, NJ: Transaction.

Stebbins, R.A. (2016a). Costs, constraints, and perseverance: a rejoinder to Lamont, Kennelly, and Moyle. Journal of Leisure Research, 48, 1-4.

Stebbins (2016b). Dumazedier, the serious leisure perspective, and leisure in Brazil. World Leisure Journal, on-line at: http://dx.doi.org/10.1080/16078055.2016.1158205.

Super, D.E. (1980). Life-span, life-space approach to career development. Journal of Vocational Behavior, 16, 282-298.

Tinsley, H.E.A., \& Eldredge, B.D. (1995). Psychological benefits of leisure participation: a taxonomy of leisure activities based on their need-gratifying properties. Journal of Counseling Psychology, 42, 123-132.

Tomlinson, A. (1993). Culture of commitment in leisure: notes towards the understanding of a serious legacy. World Leisure and Recreation, 35, 6-9.

Tsaur, S-H., \& Liang, Y-W. (2008). Serious leisure and recreation specialization. Leisure Sciences, 30, 325-341.

Unruh, D.R. (1980).The nature of social worlds. Pacific Sociological Review, 23, 271-296.

Van Moorst, H. (1982). Leisure and social theory. Leisure Studies, 1,157-170.

Veal, A.J. (1993). The concept of lifestyle: a review. Leisure Studies, 12, 233-252.

Williams, C. (1998). Is the SERVQUAL model an appropriate management tool for measuring service delivery quality in the UK leisure industry? Managing Leisure, 3, 98110.

Worthington, B. (2006). 'Getting steamed up about leisure' - aspects of serious leisure within the tourism industry. In S. Elkington, I. Jones \& L. Lawrence (Eds), Serious leisure: extensions and applications (pp.19-31). Eastbourne, UK: Leisure Studies Association. 
Table 1. Draft checklist of leisure activity-experience constructs and variables $^{1}$

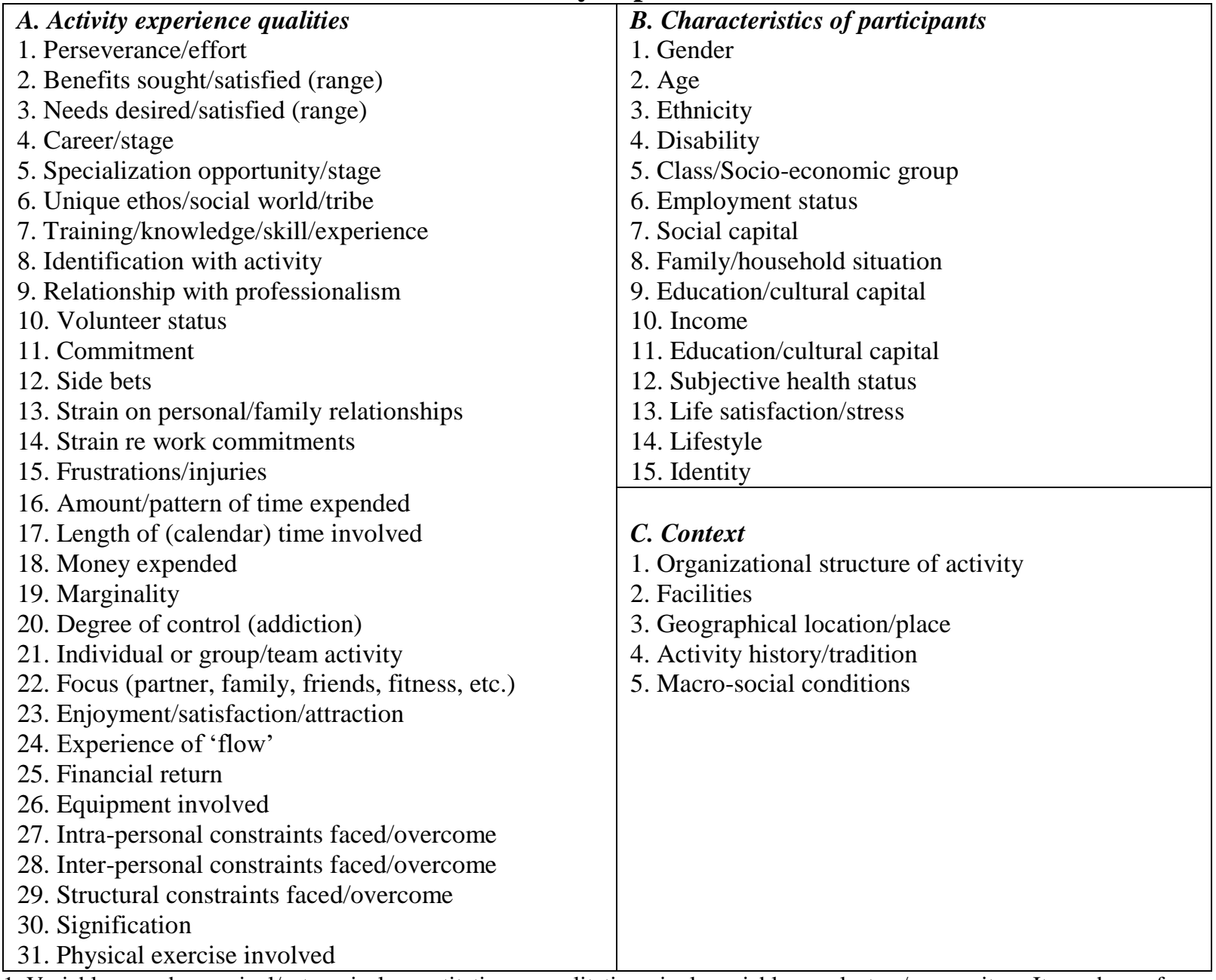

1. Variables may be nominal/categorical, quantitative or qualitative, single variables or clusters/composites. Items drawn from SLP, Needs, Benefits, Specialization, Commitment, Constraints, Involvement, leisure studies generally 


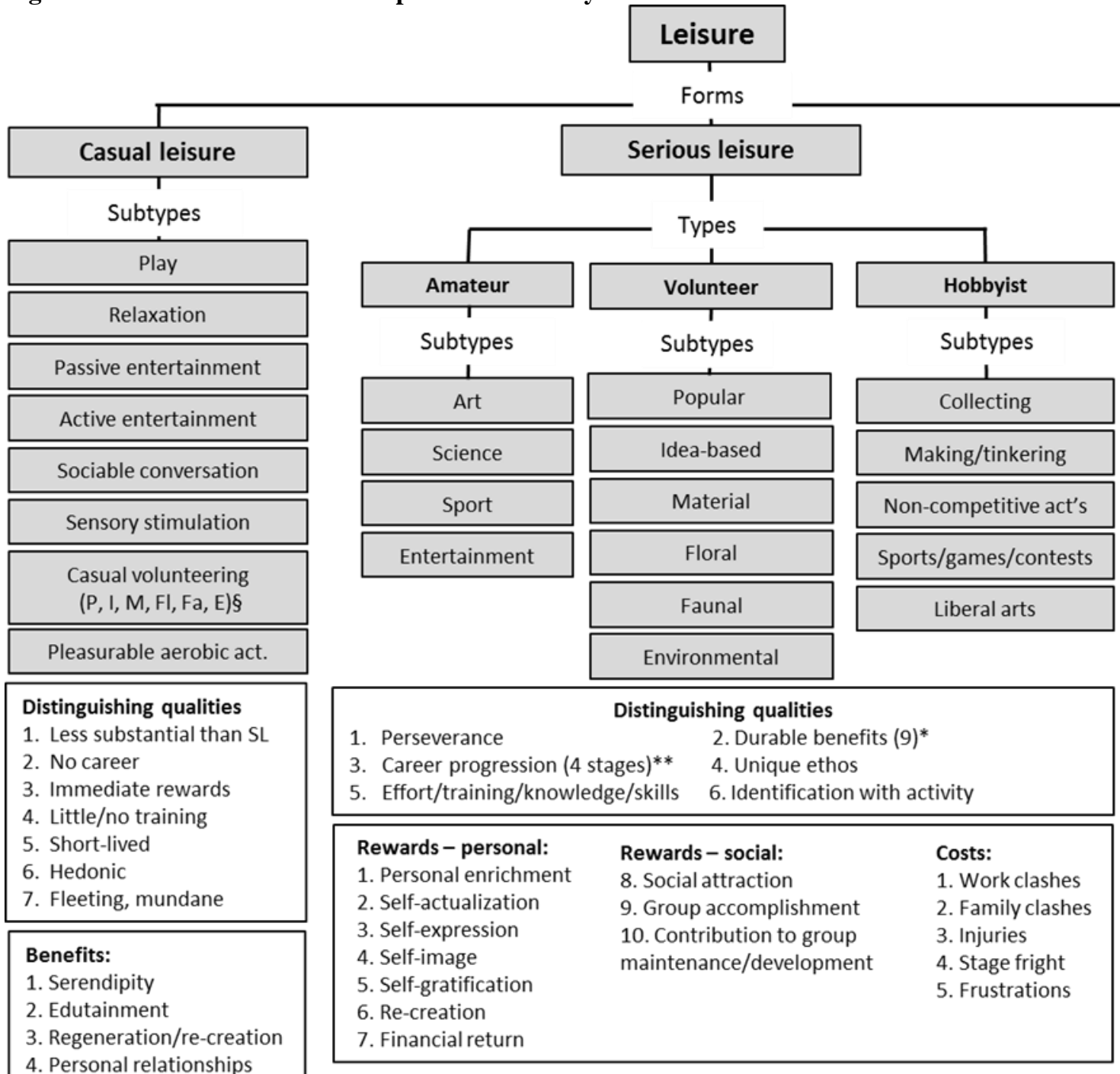

* Nine 'durable benefits': self-actualization, self-enrichment, self-expression, regeneration/ renewal, feelings of accomplishment, enhancement of self-image , social interaction/ belonging, lasting physical products, self-gratification.

\begin{tabular}{|l|}
\hline \multicolumn{1}{|c|}{ Project-based leisure } \\
\hline \multicolumn{1}{|c|}{ Subtypes } \\
\hline \multicolumn{1}{|c|}{ Making/tinkering } \\
\hline \multicolumn{1}{|c|}{ Liberal arts } \\
\hline \multicolumn{1}{|c|}{ Activity participation } \\
\hline \multicolumn{1}{|c|}{ Volunteering } \\
\hline \multicolumn{1}{|c|}{ Arts projects } \\
\hline \multicolumn{1}{|c|}{ Occasional projects $\S$} \\
\hline \hline Distinguishing qualities \\
1. Short-term \\
2. Quite complicated \\
3. One-off or occasional., \\
4. Creative \\
5. Planning \& skill required \\
\hline \hline Rewards: \\
As in serious leisure \\
Costs: not discussed \\
\hline
\end{tabular}

Key: § P, I, M, FI, Fa, E refer to: Popular, Idea-based etc. volunteering categories as under serious leisure - (Elkington \& Stebbins, 2014, p.89).

** Stages of serious leisure career: neophyte, participant, moderate devotee, core devotee 